\title{
The expressive function of colloquialisms in professional discourse: The linguopragmatic aspect
}

\author{
Elena N. Malyuga ${ }^{1, *}$, and Valentina E. Yermishina ${ }^{2}$ \\ ${ }^{1}$ Peoples' Friendship University of Russia, Faculty of Economics, Department of Foreign Languages, \\ 117198 Moscow, 6 Miklukho-Maklay Str., Russia \\ ${ }^{2}$ Peoples' Friendship University of Russia, Institute of World Economy and Business, 117198 \\ Moscow, 6 Miklukho-Maklay Str., Russia
}

\begin{abstract}
In this study the expressive function of colloquialisms is examined through the lens of linguopragmatics using the material from professional discourse, which is marked by a strict structure of expressing ideas. The study identifies expressive means of influencing the recipient and traces general trends of using colloquialisms in the English-language mass media texts as well as transcripts of business talks held between some major companies. The paper elucidates the concept of linguopragmatics and defines the subject of studies within this discipline, as well as addresses notions of colloquialisms and their expressive function. We have found that colloquialisms are increasingly used in professional discourse. The study provides an overview of the concept of lexical-semantic field, as colloquialisms are mostly actualised at the lexical level. The authors investigate the lexical-semantic field "to invest money" comprised of colloquialisms from English-language mass media outlets, along with colloquialisms used in transcripts of large companies. The following expressive means of producing an influence on the recipient have been found in the texts: bold type, capitalisation of each word, italics, numerals, capitalisation of abbreviations (the graphic level); phrasal words, metaphors, allusions, positive particles, abbreviations, epithets, short forms of nouns (the lexical level); declarative sentences, interrogatory sentences, parcellation, antithesis, parallel structures (the syntactic level). The expressive function of colloquialisms is widely reflected in professional discourse. After comparing the use of colloquialisms in mass media texts and talks transcripts we found that the most frequent expressive means are declarative sentences at the syntactical level and metaphors at the lexical level.
\end{abstract}

\section{Introduction}

Quite a few researchers point out the importance of the communicative role of colloquialisms as the oral non-codified communication domain in the national language. However,

\footnotetext{
* Corresponding author: malyuga-en@rudn.ru
} 
colloquialisms are increasingly used in professional discourse: both in the professional sections of the English-language mass media outlets and during talks - in the written and oral forms alike.

The expressive function of colloquialisms is primarily fulfilled at the lexical level. The words of a language make up associative groups, therefore, should be studied from the perspective of the lexical-semantic field consisting of a core, a centre, and a periphery.

The linguopragmatics approach is the backbone of this research. We analyse the utterance, its meaning and context, as well as the parameters of the addresser and the addressee.

The purpose of this study is to investigate the expressive function of colloquialisms in professional discourse from the perspective of linguopragmatics. This involves addressing the following tasks: 1) analysing colloquialisms encountered in mass media and in the transcripts of talks held at large companies; 2) identifying the expressive means that help make an impact on the recipient; 3 ) conducting the comparative analysis of colloquialisms at the lexical level (mass media outlets and transcripts of business talks).

The relevance of this research stems from scholarly interest towards the expressive function of colloquialisms and its role in professional discourse in the context of linguopragmatics. The study seeks to identify the impact-producing means in professional discourse and compare the use of colloquialisms in mass media and business talks transcripts.

\section{Material and methods}

The study of the expressive function of colloquialisms is based on the material from the professional discourse, specifically the analytical newscasts from the electronic versions of The New York Times, Business \& Human Rights Resource Centre, The Financial Times and The Guardian falling under "Business", "Latest News", "UK Politics \& Policy" and/or "Money" categories, which provide information in the fields of business, technologies, politics, science, culture and many other subjects targeted at a wide audience of economists, entrepreneurs and representatives of a number of other professions. The research material also includes the transcripts of business talks held on Facebook, the world's largest social network, and Instagram, a photo and video sharing social networking service; as well as the transcript of the press conference on TTIP (Trans-Atlantic Trade and Investment Partnership) - the free trade agreement between the European Union and the USA. The study used continuous sampling, descriptive, context-based and comparative methods of research.

\section{Theoretical background}

\subsection{The linguopragmatic approach}

Peirce [1] is considered the founder of linguopragmatics as a discipline that originated in the 19th century. Its active development fell on the second half of the 20th century, when the Oxford school of linguists laid that foundation for linguopragmatics related to many other linguistic disciplines, such as rhetoric (eloquence), semantics, syntax, stylistics, etc.

Today, there is no single interpretation of the term "linguopragmatics". Ariel [2] defines it as the attitude of the speaker to reality, content of the message and addressee fixed in a language unit (a lexeme, an affix, a grammeme, or a syntactic structure). According to Õim [3], the object of pragmatics research includes communicative realisations of sentences and texts. In general terms, this discipline studies a speech situation consisting of an utterance, its meaning and context, addresser and addressee [4]. Apart from that, this approach may be useful to analyse both content and purposes of colloquialisms use. 


\subsection{The notion of colloquialisms and their expressive function}

The 20th century saw the emergence of a number of studies highlighting the importance of the communicative role of colloquialisms for the speakers of the national language $[5,6,7]$. As of now, there is no single approach to the definition of colloquialisms, most generally treated as one of the forms of the national language, along with dialects, jargon speech and literary language, making up the spoken non-codified domain of the all-national speech communication together with the vernacular and jargons [8]. Colloquialisms are a lexicalgrammatical category, a functional type of the national language [9], representing words and grammatical forms of mass urban language used in the literary language as a stylistic means to attach a humorous, derogatory, ironic, or rude connotation $[10,11,12]$. The specific features of colloquialisms are spontaneity, non-normativity, substandard nature, as well as their functional and pragmatic focus [13].

The difference between the notions of "colloquialisms" and "slang" remains blurred in linguistics, with "slang" used to denote colloquialisms, neologisms, dialect and jargon words and expressions, and much more [14]. Their common feature is the emotional and expressive nature which is typical of the stylistically substandard lexis. Hence, our study uses these notions interchangeably.

Colloquialisms are widely utilised in the language of mass media. The key style-forming trend in the language of newspapers is manifested in using colloquial vocabulary, especially the colloquial-emotional and colloquial-expressive lexis in printed media $[15,16]$. The emotionally charged vocabulary gets increasingly popular in professional discourse despite the rigid structure and standards of expressing ideas that are typical of it. Therewith, the actualisation of colloquialisms is fulfilled predominantly at the lexical level, so there are good reasons to study them within the boundaries of the lexical-semantic field: the system connections of colloquialisms manifest themselves at the semantic fields level [17].

\subsection{The notion of the lexical-semantic field}

At the moment, many studies of the language vocabulary rely on the lexical-semantic approach, as it is universal in linguistics and allows analysing the lexis of any language [18]. The theory is based on the idea that several semantic groups may contain the same language units, as the lexis of a language is a system: words do not exist by themselves but rather are groups of associative units united by their semantic similarity [19].

One of Ipsen's [20] works offers an interpretation of a semantic field as a totality of words possessing a common meaning. Trier [21] was relying on this term as well when forming the relevant norms of the system-based studies of lexis. According to him, the core of the system is a source of meaning for all the units of the field that are in turn connected to each other.

Weisgerber [22] and Reuning [23] investigated the paradigmatic fields consisting of various lexical units united by a certain semantic attribute (lexical-semantic groups of words, synonyms, antonyms and others). At the same time Porzig [24] undertook a study of syntagmatic fields which represent groups of words that are interconnected in their use but are not featured/located in one and the same semantic(al) position. In his study, the scholar points out that any change(s) in semantic combinations (e.g. changing the nature/type of a verb) directly transform(s) the semantic field on the whole.

The core, the centre and the periphery are the semantic structure of the field. The core is a hyperseme - a lexical unit that is the semantic dominating idea expressing a common invariant meaning. The centre of the field is comprised of units that have a meaning that is shared with the core. The periphery consists of units most detached from the core in terms of their meaning. Thus, having the core-peripheral structure the lexical field breaks down into various micro fields that unite units according to several common semantic principles [25]. 
One of the methods to single out words into one lexical-semantic field is the contextual analysis method intended to study words in their connections with other words in a text [26]. This is the overarching approach of this study, as it investigates the paradigm of colloquialisms making up the lexical-semantic field "to invest money".

\section{Results}

\subsection{Analysis of colloquialisms found in mass media}

Let us proceed to the analysis of the English-language professional discourse where we found colloquial verbs that comprise the lexical-semantic field "to invest money":

1) ante up - to pay one's contribution, put one's money in the common pot;

2) dig down - to be generous, as if one were reaching deeply into one's pocket for lots of money;

3) dip into - to spend some of your money on something;

4) stump up - to pay the amount of money for something that somebody asks, often when you do not want to;

5) pony up - to pay; a synonym for "pay up" or "fork out";

6) tie up - to invest money so that it is not easily available for use.

The core of this lexical-semantic field is the common seme with a neutral meaning "to invest money" - "tie up". The center of the field is represented by the lexical units with a negative connotation: "dip into", "stump up", and "pony up", while the periphery has the colloquial verbs with a positive connotation "ante up" and "dig down".

The analysis of articles published in "Business", "Latest News", "UK Politics \& Policy" and "Money" columns found that the expressive function of colloquialisms is fulfilled at the following linguistic levels: the graphic, the lexical and the syntactic ones.

Let us first outline the attributes typical of all the examples studied. At the lexical level, the factual material is comprised of phrasal verbs with an emotional and evaluative connotation. At the syntactic level, all the analysed sentences are declarative and are used by the authors to convey some information to the readers.

Below are some examples from the Business section of The New York Times and The Guardian.

Executive Life; Executives Ante Up, and Win Some Skills [27].

At the graphic level, this headline utilises capitalisation of every word, italics and bold type in order to attract readers' attention and emphasise the content of the article. The publication talks about gambling and useful skills that may be acquired through playing them, which is critically important, say, for heads of companies, as they should be able to competently assess risks, make the best of their own strengths and cope with stress. At the lexical level, an emotionally charged image is created through using the allusion "ante up" ("to pay one's contribution, put one's money in the common pot") to the game of poker, where this expression would mean "to make the first bet" (or "open the pot"). At the syntactic level we can see parcellation, where the general theme ("Executive Life") is separated from its more concrete version via a semicolon ("Executives Ante Up, and Win Some Skills") to make the expression sound more rhythmic.

Let us consider the next example.

The developed countries that have had a stranglehold on the Fund since it was created in 1944 are strapped for cash while the bigger emerging countries like China and India are reluctant to pony up more cash until they secure the influence to which their economic clout entitles them [28]. 
At the graphic level, this sentence uses a mathematical symbol, namely the figure "1944", which renders the text more concise and clearer when mentioning the year. The information from this sentence is repeated in the sub-headline, which utilises bold type to produce an emotional impact on the audience. At the lexical level, the metaphor "pony up" ("to pay", "to fork out") has a negative connotation when expressively conveying the image of major developing countries that are reluctant to contribute more money to the International Monetary Fund until they reach the level of influence that corresponds to their economic might.

Canada grudgingly stumps up billions for General Motors [29].

The graphic level is manifested through bold type, which is typical of emphasising headlines. At the lexical level, the metaphor "stump up" ("to pay the amount of money for something that somebody asks, often when you do not want to") is employed with the view to expressively reflect Canada's reluctance to invest large sums of money into General Motors, the largest American automobile corporation, during a downturn. The expressive means of the syntactic level is the antithesis "stumps up billions" (meaning "reluctantly invests billions of dollars"), which is used to contrast the notions.

Next, let us take a look at another example from the same article which again features the colloquial verb "pony up".

A conservative with free market instincts, Harper sounds far from thrilled at having to pony up cash: "Today's announcement is a regrettable but necessary step to protect the Canadian economy during the worst global recession in half a century" [29].

At the lexical level, the metaphor "pony up" ("to pay", or "fork out") is semantically synonymous with the colloquial verb "stump up". At the syntactic level parcellation is used - through using a colon the sentence is split into two independent segments: the introductory explanation and the direct speech proper, which creates the participation effect for the readers and make them feel as if they were present when the speech was being delivered.

Firms under strain as they tie up money in stockpiling materials, says Santander [30].

At the graphic level, this sub-heading is typed in bold, thus expressively showcasing the key idea of the article. At the lexical level, the metaphor "tie up" ("pull off, or clinch, the deal") produces an emotional impact on the readers, communicating the idea that UK companies struggle, as they have to invest large amounts into making supplies of raw materials, thus "freezing" their funds during the preparation for the no-deal Brexit. The syntactic level features parcellation, which splits the utterance into two sentences using a comma: the theme of the article ("Firms under strain as they tie up money in stockpiling materials"); and a link to the source ("says Santander") - Spain's largest financial and credit group. As a result, the phrase becomes balanced.

The next example to examine is a headline from the Latest News section of the Business \& Human Rights Resource Centre organisation.

In crises, mankind becomes the business of business: Capitalists ante up for tsunami victims [31].

In this headline, we can see bold type at the graphic level, which is widely used in both printed and web-based texts. The lexical level employs the allusion "ante up" ("pay one's contribution", "pay up"), as is the case in the example considered above. Finally, at the syntactic level, the author of the article uses parcellation dividing independent semantic fragments with a colon: the idea that even businesses have to resolve all-human problems during crises ("In crises, mankind becomes the business of business"); and capitalists provide financial aid for tsunami victims ("Capitalists ante up for tsunami victims").

Another case in point is an example from the UK Politics \& Policy section of The Financial Times.

London homeowners dig down as property prices shoot up [32]. 
The lexical level is represented by the metaphor "dig down" ("to be generous, as if one were reaching deeply into one's pocket for lots of money"), which vividly demonstrates the necessity of London homeowners to spend large sums of money due to a drastic surge in real estate prices. In terms of syntax, parallel structures serve as an expressive means: "London homeowners dig down" and "as property prices shoot up". They fulfill emphasising and image-creating functions. In addition, we can see the concurrent use of the antithesis through the setting off the notions "dig down" and "shoot up" as a means of making an impact on the audience.

The next example is from the Money section of The Guardian.

Nearly half of parents admit to being "piggy bank raiders" who occasionally dip into their children's cash to cover costs such as parking, takeaways, taxis, school trips and paying the window cleaner [33].

The expressive function of colloquialisms is fulfilled through the metaphor "dip into" ("to spend some of your money on something'), which in this case reflects the fact that many parents have to "dig into" their children's pocket money to cover expenses for parking, food and many other things.

\subsection{Analysis of colloquialisms found in business talks transcripts}

Let us turn to the linguopragmatic analysis of business transcripts of large companies. Their social and status-based parameters as well as the conditions and purposes of speech acts are as follows. The Facebook company being the world's largest social network held talks in 2012 about acquiring Instagram, a photo and video sharing social networking service; the talks were held in the format of e-mail exchange. The Transatlantic Trade and Investment Partnership (TTIP) is the planned free trade agreement between the European Union and the USA that was discussed during a press conference in 2014.

Talks are characterised by the official type of speech, yet the use of colloquialisms attaches a colloquial connotation to the dialog between two parties. The following colloquialisms have been found in the business talks transcripts:

1) $A S A P$ - immediately, as soon as possible;

2) awesome - great, excellent;

3) btw - used in computer message shorthand to mean "by the way";

4) congrats - abbreviation for "congratulations";

5) (looking) fwd - a short way of writing "forward";

6) FYI - used in computer message shorthand to mean "for your information";

7) great-emphasising that you are pleased or enthusiastic about something;

8) hang - to spend time with someone;

9) leak - to give secret information to the public, for example by telling a newspaper;

10) wrap it up - to finish, often in order to stop doing something annoying;

11) yeah - a variant of "yes".

Let us consider these colloquialisms in the context of talks between companies. First, let us examine the colloquialisms encountered in the talks between Mark Zuckerberg, Facebook founder and CEO, and Kevin Systrom, founder and CEO of Instagram. Notably, those talks were held in the format of electronic business correspondence. The one common thing for all the examples is an abundant use of abbreviations and that the majority of sentences are declarative.

FYI, apparently it leaked to the Wall Street Journal that we and Twitter were talking to you about acquisition [34].

At the graphic level, we can see the capitalisation of the abbreviation "FYI" ("For Your Information"), which makes us perceive the utterance as fast-paced and informal. At the lexical level, the communicative situation is created through the use of abbreviations that are 
common for e-correspondence, which makes the phrase sound fluid. The metaphor "leak" ("reveal a secret") expressively conveys Mark Zuckerberg's concern about the information about Instagram acquisition "leaking" into mass media.

$\boldsymbol{B T W}$, I've already eaten, but I'm happy to go out and grab some food if you're hungry [34].

The graphic level is represented through the use of capitalisation - "BTW" ("by the way". "incidentally"), which attracts the recipient's attention to the gist of the utterance. At the lexical level, this abbreviation reduces the formality of communication when discussing the terms of a business meeting.

Looking fwd to hanging [34].

At the lexical level, the abbreviation "fwd" ([look] forward [to something]) creates an informal atmosphere in the context of a business exchange. The metaphor "hanging" ("goof off", "spend the time purposelessly") vividly shows Kevin Systrom's enthusiasm about his upcoming meeting with Mark Zuckerberg and introduces the touch of informality to their communication.

Any chance we could meet ASAP? [34].

The graphic level sees the use of the "ASAP" abbreviation ("as soon as possible") in all caps to attract the interlocutor's attention to the need to meet up as soon as possible. At the lexical level, this abbreviation establishes more confidential relations between the participants. At the syntactic level this sentence is interrogatory.

Congrats on the Android launch [34].

The lexical level features the short form of the noun "congrats" ("congratulations"). This makes the phrase more fast-paced and decreases the formality of the communicative situation.

Great, see you in a bit [34].

Awesome. I'm at home but let me know if there's anything I can help out with [34].

At the lexical level, these sentences contain the epithet "great" ("wonderful", "perfect") and "awesome" ("splendid"), which expressively reflects the satisfaction of both parties with the agreements achieved.

Secondly, let us analyse the examples of colloquialisms used during the concluding press conference of the fifth round of talks about the Transatlantic Trade and Investment Partnership. We have to note that in their speech the participants stick to the formal business style, with the use of colloquial expressions being kept to a minimum.

Yeah, we have a lot of regulators participating in the round in the range of regulatory areas [35].

The affirmative particle "yeah" ("yes") is encountered eight times in the speech of the talk's participants. In this example, it acts as a responsive structure at the lexical level, which confirms the above expressed opinion that the USA have a multitude of regulating bodies for specific purposes. The use of this particle imparts coherence and integrity to the dialog.

You're not supposed to - not to do follow-ups, so just wrap it up [35].

At the lexical level, the metaphor "wrap it up" ("to successfully complete a business deal", "to finish") is used by conference participants with the purpose to politely and emotionally address the press representative with a request to stop the flow of his questions as the speaker wishes to answer other questions as well - "I want to get more questions".

\section{Discussion}

To conduct the linguopragmatic analysis of colloquialisms, we have compared the use of colloquialisms and their expressive function in English-language mass media and transcripts of talks held at large companies. 
A linguopragmatic analysis requires identifying the social and status-based parameters of the addresser and addressee [36]. To look into colloquialisms found in mass media, we used articles sourced from well-known daily and business printed media outlets: The New York Times, Business \& Human Rights Resource Centre, The Financial Times, and The Guardian. The conditions of the speech acts under study are e-versions of articles posted on the official websites of said outlets. Their goal is to cover news, while the goal of the audience is to take notice of them.

Overall, we examined 200 sentences. From the perspective of linguopragmatics of professional discourse, we identified expressive means of producing an impact on the recipient in the English-language mass media texts (Figure 1).

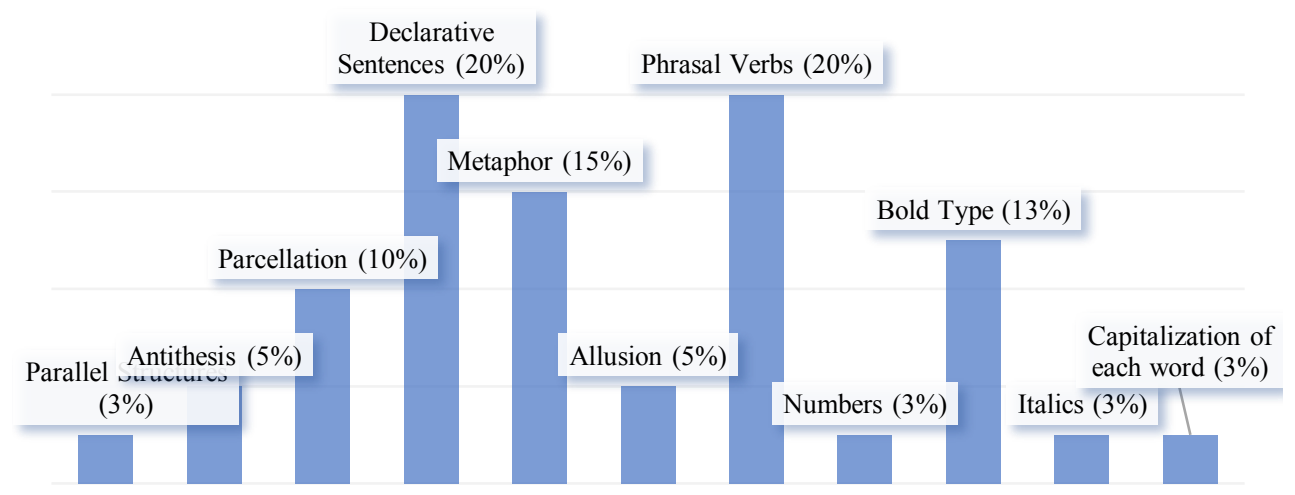

Fig. 1. Expressive means of influencing the recipient in mass media.

The most common ones are declarative sentences $(20 \%-200$ examples $)$ at the syntactic level; phrasal verbs $(20 \%-200$ sentences $)$ and metaphor $(15 \%-150$ examples $)$ at the lexical level. Next come bold type (13\% - 125 examples) at the graphic level and parcellation $(10 \%$ - 100 examples) at the syntactic level. The least frequently used are allusion $(5 \%-50$ examples) at the lexical level and antithesis (5\% - 50 examples) at the syntactic level as well as capitalisation of each word $(3 \%-50$ examples) at the syntactic level, italics $(3 \%-25$ examples) and numerals (3\% - 25 examples) at the graphic level and parallel structures (3\% -25 examples) at the syntactic level.

Having explored colloquialisms found in business talk transcripts, we were able to find expressive means of producing an impact most commonly used in this type of communication (Figure 2).

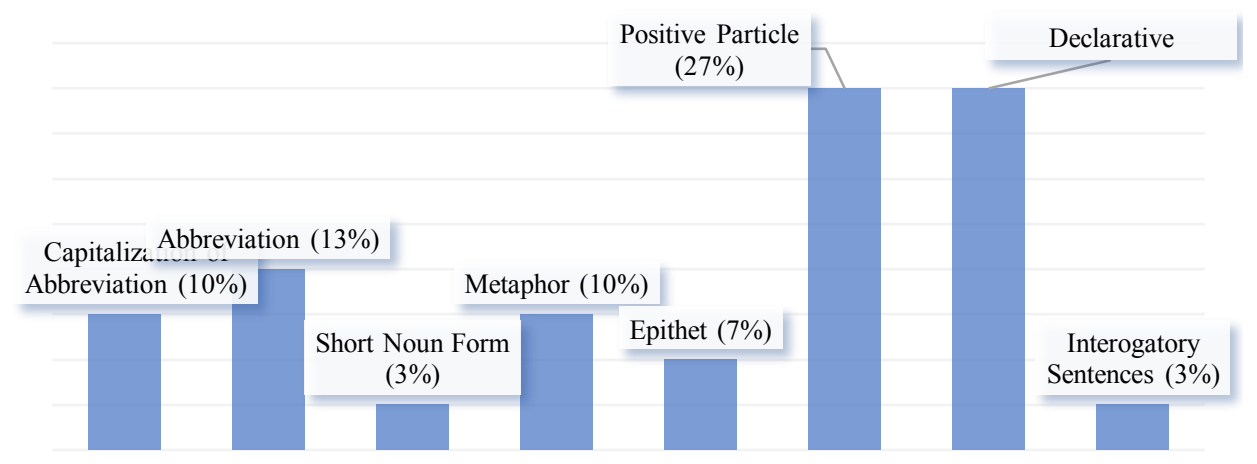

Fig. 2. Expressive means of influencing the recipient in business talks transcripts 
The most widespread ones are declarative sentences $(27 \%-8$ examples $)$ at the syntactic level and positive particles $(27 \%-8$ examples) at the lexical level. Next come abbreviations $(13 \%-4$ examples) and metaphor $(10 \%-3$ examples $)$ at the lexical level, as well as capitalisation of abbreviations (10\% - 3 examples) at the graphic level. The most frequently used are epithets $(7 \%-2$ examples) and short form of noun $(3 \%-1$ example) at the lexical level; interrogatory sentences $(3 \%-1$ example) at the syntactic level.

\section{Conclusion}

Having analysed the colloquialisms making up the lexical-semantic field "to invest money" using the material from the professional sections of English-language mass media outlets and colloquialisms encountered in talks transcripts of large-scale companies, the study has identified the following expressive means of making an impact on the recipient: at the graphic level - bold type, capitalisation, italics, numerals, capitalisation of abbreviations; at the lexical level - phrasal verbs, metaphors, allusion, positive particles, abbreviations, epithets, short noun forms; at the syntactic level - declarative sentences, interrogatory sentences, parcellation, antithesis, parallel structures.

After comparing the use of colloquialisms in mass media outlets and talks transcripts we may arrive at the conclusion that the most common expressive tools among colloquialisms in professional discourse are declarative sentences. This is because through declarative sentences the audience receives some information, while metaphors convey a certain idea in an expressive way.

\section{References}

1. C.S. Peirce, Pragmatism and pragmaticism (Harvard University Press, 1965)

2. M. Ariel, Defining pragmatics (Cambridge University Press, 2010)

3. H. Õim, Journal of Pragmatics 1(3), 251-267 (1977) 10.1016/0378-2166(77)90037-6

4. E.N. Malyuga, S.N. Orlova, Linguistic pragmatics of intercultural professional and business communication (Springer, 2018), 10.1007/978-3-319-68744-5

5. D. Crystal, New Blackfriars 46(534), 148-156 (1964) 10.1111/j.17412005.1964.tb07472.x

6. E. Partridge, A dictionary of slang and unconventional English (Routledge, 1984)

7. F. De Saussure, Literary theory: An anthology (Blackwell Publishing, 2004)

8. E. Banks, Financial lexicon (Springer, 2004)

9. R. Salah, Advances in Language and Literary Studies 6(3), 1-9 (2015) 10.7575/aiac.alls.v.6n.3p.1

10. S. Nevalainen, Across Languages and Cultures 5(1), 67-88 (2004) 10.1556/Acr.5.2004.1.4

11. E. Monakhova, Training, Language and Culture 3(1), 37-52 (2019) 10.29366/2019tlc.3.1.3

12. E.N. Malyuga, A. Shvets, I. Tikhomirov, Proceedings of 2016 SAI Computing Conference, 229-232 (2016) 10.1109/SAI.2016.7555987

13. J. Yang, C. Yin, Journal of Technology and Chinese Language Teaching 9(1), 35-47 (2018)

14. C. Eble, Sociolinguistics (De Gruyter Mouton, 2008)

15. D. Landert, Personalisation in mass media communication (John Benjamins, 2014) 
16. L.L. Baranova, N.L. Kriakina, Training, Language and Culture 4(3), 31-42 (2020) 10.22363/2521-442X-2020-4-3-31-42

17. D. Kastovsky, The Cambridge history of the English language (Cambridge University Press, 1992)

18. E.N. Malyuga, B. Tomalin, Journal of Language and Literature 5(4), 172-180 (2014)

19. M. Vanhove, From polysemy to semantic change (John Benjamins, 2008)

20. G. Ipsen, Zeitschrift für Deutschkunde 46, 4-18 (1932)

21. J. Trier, Aufsätze und Vorträge zur Wortfeldtheorie (Walter de Gruyter, 2013)

22. L. Weisgerber, Muttersprache 70, 1-6 (1960)

23. K. Reuning, A comparative study of the linguistic field of pleasurable emotions in English and German (College Bookstore, 1941)

24. W. Porzig, Das Wunder der Sprache. Probleme, Methoden und Ergebnisse der modernen Sprachwissenschaft (Francke Verlag, 1967)

25. M.C. L'homme, Lexical semantics for terminology (John Benjamins, 2020)

26. M. Vakulenko, Journal of Quantitative Linguistics 26(2), 116-128 (2019) 10.1080/09296174.2018.1452524

27. M. Alboher Nusbaum, The New York Times (2003) https://www.nytimes.com/2003/02/09/business/executive-life-executives-ante-up-andwin-some-skills.html

28. L. Elliott, The Guardian (2012) https://www.theguardian.com/business/economicsblog/2012/apr/03/imf-christine-lagarde-more-money

29. A. Clark, The Guardian (2009) https://www.theguardian.com/business/andrew-clarkon-america/2009/jun/01/generalmotors-canada

30. J. Jolly, The Guardian (2019) https://www.theguardian.com/business/2019/jan/18/ukmanufacturers-hard-brexit-stockpiling-santander

31. G. Lamphier, Business \& Human Rights Resource Centre (2005) https://www.businesshumanrights.org/en/latest-news/in-crises-mankind-becomes-the-business-of-businesscapitalists-ante-up-for-tsunami-victims

32. T. Johnson, Financial Times (2016) https://www.ft.com/content/9ace5c08-d4bc-11e5$829 \mathrm{~b}-8564 \mathrm{e} 7528 \mathrm{e} 54$

33. G. Fuller, The Guardian

https://www.theguardian.com/money/2016/may/02/piggy-bank-raiders-parentschildrens-savings-survey

34. TechCrunch, SCRIBD (2020) https://ru.scribd.com/document/470826155/HouseJudiciary-Facebook-text-log-between-Mark-Zuckerberg-and-Kevin-Systrom

35. The USTR Archives, The USTR Archives (2014) https://ustr.gov/about-us/policyoffices/press-office/speeches/transcripts/2014/May/Transcript-from-Closing-PressConference-Fifth-Round-TTIP-Negotiations

36. E.N. Malyuga, B. Tomalin, Training, Language and Culture 1(1), 28-45 (2017) 10.29366/2017tlc. 1.1 .2 